\title{
ESTÉTICAS PERIFÉRICAS NA CIDADE
}

\section{Resumo:}

A cidade contemporânea se expande hoje nas periferias que constituem um formidável e heterogêneo movimento de formas, paisagens, modos de organização e modos de vida. A periferia oferece um potencial de experimentação tanto para os atores que as constroem, como pelos habitantes que as vivem e os pesquisadores que as analisam, obrigando-os a pensar fora das categorias estabelecidas. Na dinâmica midiática, processos de inclusão e exclusão, de globalização e de proximidade se cruzam e negociam para criar espaços de sustentabilidade e acesso à cidadania por meio de maior intervenção dos atores periféricos.

\section{ESTÉTICAS PERIFÉRICAS NA CIDADE}

“Me perdoem, mas desconfio de muita coisa. Todo mundo está correndo pelo seu - e isso é um fato -, mas tem umas atitudes em que a favela, ou nossa periferia, ou a comunidade, seja como você a chama, está em último plano".

Ferréz ${ }^{1}$

\section{Poéticas do espaço}

As discussões em torno do investimento/esvaziamento simbólico do espaço, seja ele público, privado, urbano, vêm se multiplicando na atualidade. A velocidade das transformações

\footnotetext{
${ }^{1}$ FERRÉZ. “Antropo(hip-hop) logia”. In: Folha de S. Paulo, 5 de abril de 2006, p. A3. Opinião.
} 
contemporâneas faz com que sempre mais o espaço não seja visto como algo de exterior ao sujeito, seu cenário, coisa extensa, passando a elemento constitutivo de sua estruturação. Pensar a crise que atinge o homem contemporâneo é pensar seu imaginário, os processos de subjetivação, suas representações do tempo e do espaço. Melhor, do espaço/tempo. Os enfoques do assunto, nos diversos campos do saber, vão dos apocalípticos espaços desertificados pelo progresso, pelos fluxos globais e espaços virtuais ao apelo às cidades referenciais, com histórias e memórias bem construídas. Nos interstícios dessas duas posições extremas, constroem-se outros imaginários espaciais, criados pelo investimento pontual de pessoas e grupos, desenha-se a possibilidade do reinvestimento simbólico, seja no real, seja no virtual.

Não mais o espaço cartesiano que dominou o funcionalismo modernista, mas espaço fenomenológico, extensão humana. Cidades invisíveis sob o concreto das estradas, o vão dos viadutos, os arcos, as pontes, os castelos e as cúpulas. Nada é dado ou natural, nada é só geografia, nada tem apenas uma função, seja ela política, econômica ou administrativa. Não se pode falar de cidade em geral, sintetizar um espaço como se falou da polis grega, da Roma dos espetáculos, dos burgos medievais ou da moderna cidade industrial. Multiplicam-se as trocas simbólicas contemporâneas e a produção de espaços de acesso ou de interdição.

O diálogo de Marco Polo com Kublai Khan em Cidades invisíveis² ${ }^{2}$, de Ítalo Calvino, oferece pistas para algumas considerações sobre a representação do espaço contemporâneo. As narrativas e respostas de Marco Polo ao Imperador desconstroem a ideia da cidade/geografia, espaço concreto, das cidades afixadas no Atlas. Perde-se a versão realista, própria do século passado, cuja função era caracterizar tipos, confirmar classes e posições sociais. Também não é o cenário romântico, reduplicando os humores das personagens e afirmando a identidade exuberante do solo nacional ou mesmo o espaço do modernismo, mais preocupado com a visão política da afirmação do nacional. Não mais uma ideologia homogeneizante, generalizadora, produtora de totalidade já dada, mas o espaço como alteridade provocadora de novas inserções.

\footnotetext{
${ }^{2}$ CALVINO, Ítalo. Cidades invisíveis. São Paulo: Companhia das Letras, 1990.
} 
A fisicidade geográfica perde sua estabilidade e passa a ser visivelmente elemento coestruturante da subjetividade contemporânea nas diversas fases da crise por que passa: da desertificação do “eu”, engolido pelos simulacros da cena americana, aos investimentos mais inesperados, como assinala Pierre Sansot no livro Les gens du peu ${ }^{3}$. Perde-se o padrão - ouro de avaliação do espaço. Entra-se em uma espécie de transespaço camaleônico.

Para Octavio Ianni, ${ }^{4}$ a dispersão mundial dos processos produtivos é acompanhada pelo desenvolvimento de recursos informáticos de integração, também em escala mundial. A informática e as telecomunicações desempenham um papel importante no processo das transformações urbanas, acelerando ritmos, generalizando articulações, abrindo novas possibilidades de dinamização das forças produtivas, criando meios rápidos, instantâneos e abrangentes de produção e reprodução material e cultural. O mundo adquire características de uma imensa fábrica, acoplada com um vasto shopping center e colorido por uma enorme disneylândia. Tudo isso polarizado na rede de cidades globais desenhando o mapa do mundo.

A tensão entre o cosmopolitismo e o localismo progressivamente se acentua, culminando na descaracterização da própria cidade como centro aglutinador das experiências, produção e reflexão da condição moderna. Ao modelo fordista adiciona-se, no cenário pós-moderno desse início de século, a especialização setorializada do capitalismo flexível em que os centros de produção são dispersos e a correlação entre operário e indústria se fragmenta na medida em que as referências espaciais e os agrupamentos de classe são desestabilizados. A modernidade parece sacudir as paisagens do imaginário desenhando estranhas cartografias descentradas.

Interpretar a multiplicidade das experiências urbanas das metrópoles significa avaliar os sinais da modernidade contemporânea sem recair no determinismo tecnológico de uma distopia esvaziada de significação. Entretanto, em confronto com a indiferenciação e a desertificação inventam-se, tanto na arquitetura que abandona o ideário funcionalista quanto nos movimentos de bairro, grupos e associações públicas e privadas promovem a importância da

\footnotetext{
${ }^{3}$ SANSOT, Pierre. Les gens du peu. Paris: PUF, 1991.

${ }^{4}$ IANNI, Octavio. A era do globalismo, 2 ed. Rio de Janeiro: Civilização Brasileira, 1996. p. 70.
} 
sustentabilidade com apelo à cultura para gerar valor agregado aos produtos das comunidades chamadas a serem mais ativas. A cidade é repaginada.

\section{A cidade nos contextos globais}

Pensar a cidade hoje em tempos de globalização e a aceleração das trocas impõe o recurso à discussão do paradigma comunicacional e sua capacidade de construção de sentido; impõe o apelo aos estudos culturais para pensar a ordem e a desordem, a identidade e a diferença já que a cultura se constrói exatamente no trânsito entre esses pólos; impõe pensar as estratégias do consumo que imprimem ao imaginário contemporâneo uma mobilidade que não se deixa aprisionar pelas organizações classistas e que vivem de apropriações e negociações inesperadas. A leitura do mundo se processa sempre mais por meio de uma semiologia em que a pegada publicitária, o gosto pelo espetacular, pelo assombro, tanto pode criar uma congestão informacional, como linhas de fuga ao paradigma dominante. A cultura torna-se central neste processo urbano inscrito no mundo globalizado e o corpo e suas próteses participam e promovem sua dinâmica. As cidades se articulam ao panorama internacional sem deixar ter suas preocupações primordiais ligadas à proximidade e à capacidade criativa em seus territórios. O local e o global se recriam em contextos virtuais e também de proximidade: praças, ruas, bairros e cidades concretas relacionando o local e o global, a memória e a inovação.

A cidade contemporânea se expande hoje nas periferias que constituem um formidável e heterogêneo movimento de formas, paisagens, modo de organização e modo de vida. A periferia oferece um potencial de experimentação tanto para os atores que as constroem, como pelos habitantes que as vivem e os pesquisadores que as analisam. Participa do complexo da reorganização da cidade e é importante orientar a pesquisa no sentido não das categorias fechadas (centro e periferia), mas das situações de transição, evocando novas potencialidades. As periferias parecem obrigar os pesquisadores a pensar fora das categorias estabelecidas. Por outro lado e paradoxalmente, essa construção desses espaços se inscreve também numa dinâmica de uniformização, proveniente de modelos internacionais. É sobre este jogo entre normalização e inovação que nos perguntamos. Qual a responsabilidade dos atores políticos, 
das mídias, dos arquitetos urbanistas, dos geógrafos, nesta produção de sentido? Assim, nossa questão refere-se ao jogo dialético inovação/normalização no seio das periferias urbanas, tendo a moda como vetor. Seriam as periferias territórios à deriva? Territórios a serem contornados, barrados, murados? Ou nelas encontramos provocações para novos modos de funcionamento urbano que nos obrigam a pensar fora das categorias estabelecidas fugindo das classificações imobilizantes?.

A globalização traz em seu bojo uma abertura dos processos de identidade, uma grande variedade de “posições de sujeito”. Nas sociedades da modernidade tardia, a concepção de identidade é mais perturbadora e provisória, caracterizada por rupturas, descontinuidades e deslocamentos, em oposição às sociedades tradicionais que perpetuavam o passado. Áreas diferentes do globo são postas em interconexão, desalojando o sistema social de suas relações espaço-temporais tradicionais, provocando novas articulações e uma concepção problemática de identidade. Quanto mais a vida social se torna mediada pelo mercado global de estilos, lugares e imagens, pelas viagens internacionais, pelas imagens da mídia e pelos sistemas de comunicação, mais as identidades parecem flutuar livremente numa espécie de supermercado cultural. As novas tecnologias informáticas não são apenas instrumentos de percepção ou utensílios de produção, mas dispositivos de conexão e/ou de desconexão de formas onde o sentido se produz. Uma reciclagem atinge praticamente todos os domínios da cultura contemporânea, notadamente da tecnociência, da moda e das artes, com grande exuberância de processos de agenciamento das singularidades diferenciais.

É no interior desta dinâmica que o imaginário da moda vai, progressivamente, contaminando de homogeneização global, os lugares mais afastados e, simultaneamente, dotando de variedade locais a linguagem globalizada.

A ação das cidades aparece como uma pedra angular da Agenda 21 da Cultura, em que está é entendida como desenvolvimento solidário, luta pela liberdade, justiça e inclusão. O desenvolvimento local requer a imbricação entre as políticas culturais e as outras políticas públicas, sociais, econômicas, ambientais e urbanísticas com a participação do cidadão. O item que fala de cultura, sustentabilidade e território é da máxima importância e se articula com a criatividade das periferias para a inclusão social. O reconhecimento da dimensão 
econômica da cultura deve possibilitar e contribuir para a identidade local, a atividade criativa e a continuidade do emprego. É importante que o documento Agenda 21 da Cultura tem sido utilizado por muitas cidades para desenvolver a dimensão cultural de suas políticas urbanas, tal como Bogotá, Montreal e outras. Nosso foco vai em direção do incentivo à cultura nas dimensões citadas impedindo sua instrumentalização para fins publicitários no momento em que, sem dúvida, a periferia é uma das pautas do momento.

\section{A corporeidade na cidade: da distinção ao estilo}

O uso do termo corporeidade remete à complexidade do seu entendimento não só como biologia, cultura das aparências, mas também nas suas relações com o mundo como fator social total. O corpo não é objeto de conhecimento do qual se possa dispor, não é algo que se coloca diante de nós, mas faz oscilar a cesura que se tenta colocar entre o pesquisador e ele mesmo. A questão da corporeidade representa uma interrogação contemporânea à sociedade da imagem, fotográfica e cinematográfica no momento em que ela diz respeito tanto às sociedades que se constroem, quanto aos conhecimentos que estudam suas ficções. A pergunta chega junto com a crise da matriz cientista e a passagem do conhecimento à imprecisão, instabilidade e à emoção. No lugar da segurança, ameaça da abjeção. Ora, o urbano a que somos convocados hoje não é mais a cidade como território, como gestão de espaços, como distribuição de atividades, mas de uma relação à cidade onde a corporeidade desempenha uma intrigante evidência e impregna a cidade, perturbando as categorias clássicas (dentro/fora, privado/público, real/imaginário, aqui/lá). O urbano faz surgir não uma confusão, mas ambiguidade, temporalidade onde a fugacidade perene, o traçado invisível tornam-se elementos ativos na maneira de fazer e de sentir. Não é mais somente o indivíduo que se localiza na cidade. É uma relação consigo mesmo que se complica com a intervenção da aventura urbana. Novas relações com o mundo surgem e dão lugar ao indecidível, ao indeterminado e ao indefinido, apesar do desejo contemporâneo de uma comunicação generalizada e transparente.

Focalizamos a moda como fator de mobilidade social e individual, atitude cultural que entre outras artes vem acentuar o caráter dinâmico da cena contemporânea, trabalhando com o 
imaginário de misturas. Agora ela passeia pela periferia. Lugares como Caxias, município da baixada fluminense tornam-se on. Seu centro de confecções festejou o sucesso com desfile de Carlos Tufvesson em passarela estendida na Praça do Pacificador, foco do Fashion Caxias. Travestis desfilam na Mem de Sá criações próprias e param o trânsito da Lapa. Unhas postiças enormes, argolões dourados e lenço Louis Vuitton na cabeça, Luana Muniz declara enfática: "queremos mostrar que somos úteis e visíveis na sociedade". A visibilidade urbana estimula a moda que, segundo Georg Simmel, se não quer mudar o mundo, pretende arrumálo com um novo olhar. Ela ressemantiza o espaço e, na sua dimensão simbólica, organiza a vida social por meio das aparências partilhadas pelos diversos grupos. A publicidade e o consumo são alguns vetores desta construção de superfícies em que o sentido desliza jogando com o up and down dos indivíduos e lugares. Ser cutting edge é importante para se distinguir da massa e, sobretudo, os jovens de tribos diversas parecem estar sempre prontos para um clic.

Tradicionalmente a moda tinha uma função de distinção, como acentuou Bourdieu, e os espaços e fronteiras acompanhavam a ordenação das classes, profissões, gêneros, faixasetárias. Balzac soube ler essas diferenças. Na história, alguns movimentos que marcaram a moda encarnavam revoltas pelo estilo e a desconstrução do mood anterior. Patrice Bollon, em A moral da máscara, narra a verdadeira luta simbólica das diversas manifestações marcadas pelos artifícios da aparência: Merveilleux, Zazous, Dândis ou Punks, são alguns dos exemplos.

Se os anos 50 pertenceram a Copacabana, primeira praia a lançar moda, nas décadas seguintes novos points da Zona Sul e do Brasil fizeram eco nos jornais, revistas e blogs, determinando atitudes e comportamentos. A importância das ruas na moda tem um momento chave nos anos 60, quando se desenvolve o sport-wear e a moda unissex. Londres dita moda. As butiques se disseminam. Carnaby Street ou Kings Road tornam-se verdadeiros cenários entre música contínua, luzes, num entra-e-sai em que o movimento da rua é incorporado ao comércio. Progressivamente, a cidade oferece novas possibilidades tornando-se sempre mais inesperada, transversal. Nem mão, nem contramão. Tudo parece ser permitido e a velocidade da mudança dos trajetos caminha em ziguezague. Seqüencialmente, acelerou-se a desconstrução das 
oposições e multiplicaram-se os looks, a partir de novos dados culturais. A moda de rua inspira sites, blogs, fotologs e as tendências são simultâneas e em rede.

O movimento fashion, sempre mais fluido, parece obedecer a duas estratégias principais, uma delas conta as novidades como segredos e encontra verdadeiros cofres para os fashionistas. Ruas de bairros nem tão nobres escondem jovens estilistas que se associam para mostrar seus produtos. Em contrapartida, temos movimentos de ocupação geral como o Fashion Rio, São Paulo Fashion Week, feiras diversas e um pontilhado kitsch de camelôs. A construção do tempo/espaço urbano vai interferindo no imaginário das pessoas que se sentem aventureiras em suas descobertas das senhas de acesso fashion ou incluídas nas grandes festas. A cidade vira locação e cenário. Simultaneamente, o shopping vira cidade e a rua vira mall.

Diante do esfacelamento dos paradigmas que orientaram o projeto moderno de viés normativo na sociedade do consumo e do espetáculo, a moda se produz como arquivo e vitrine do ser/parecer, fabricando selfs performáticos por meio de sutis recriações dos conceitos de verdade, de bem e de belo. Materializa-se uma est-ética.

\section{O Rio midiático}

A cidade responde aos nossos medos e desejos. É carne e pedra, pertence a nossa corporalidade e acolhe tantas versões quantos forem os olhares sobre ela; “de uma cidade não aproveitamos as suas sete ou setenta e sete maravilhas, mas a resposta que dá a nossas perguntas”. ${ }^{5}$ A cidade torna-se um caleidoscópio de padrões e valores culturais, línguas e dialetos, religiões e seitas, modos de vestir e alimentar, etnias e raças, problemas e dilemas, ideologias e utopias.

O Rio de Janeiro é exemplarmente o resultado das narrativas que se criaram e se criam nas ciências sociais, na literatura, na música e, sobretudo, na mídia, em constante interação com a vivência de seus habitantes. O Rio colonial e sua transculturação mal-ajambrada, sua lascívia e seus excessos fora do padrão da metrópole; o imaginário do luxo cosmopolita da capital

\footnotetext{
${ }^{5}$ CALVINO, Ítalo. Op. Cit., p. 44.
} 
federal se promovendo nos salões; a construção e promoção dos encantos naturais da cidade maravilhosa; e, mais recentemente, a explosão dos discursos sobre o Rio violento, sobre a cidade esquartejada, atravessada pela miséria. Impossível fixar hoje qualquer dessas imagens como preponderante. O Rio feito de points turísticos, o Rio que lança moda, é também o dos arrastões.

Diante do esfacelamento da realidade, é comum ver a mídia produzir uma espécie de curadoria da cidade, conjugando a narrativa do Rio Maravilha, Rio do turismo e da moda e o Rio violento e marginal. Neste contexto é interessante apontar o aumento da variedade narrativa sobrre a cidade que vai encontrar na periferia protagonistas para uma infindável repaginação. Nesta dinâmica surge tanto a voz das comunidades, quanto a da indústria cultural.

Carlos Diegues, um dos diretores de “5 X Favela” original, de 1961, fala da nova linguagem audiovisual do cinema de retomada sobre a periferia: "agora temos um ponto de vista diferente. Um ponto de vista de dentro. Está levando “5 X Favela” - agora por nós mesmos”. ${ }^{6}$. Este novo olhar sobre as favelas é uma constante onde a reurbanização substitui a erradicação - e a exposição de abril deste ano no Museu da Casa Brasileira, “Cidades Informais do Século 21”, dá pistas sobre esta mudança. A mudança começou no Rio que em 1968 urbanizou três favelas: Brás de Pina, Mata Machado e Morro União, gerando em 1994, Favela-Bairro. Remoção agora só quando se trata de área de risco. O programa pioneiro da Favela-Bairro marca o fim da influência do modernismo na urbanização, que previa um modelo único de cidade e encarava a favela como um desvio a ser corrigido, como sublinhou Sérgio Magalhães que atuou no programa brasileiro nessa área (www.mcb.org). ${ }^{7}$

Hoje, a mídia dá destaque espetacular às mudanças das favelas e à valorização dos imóveis em seu entorno. Tal fato parece desviar-se do espírito da Agenda 21 para deixar que o fator econômico se transforme no vetor principal das negociações. Compram-se casas, alugam-se

\footnotetext{
${ }^{6}$ FONSECA, Rodrigo. “O morro vai a Cannes”. O Globo, 16 de abril de 2010, p. 1. Segundo Caderno.

${ }^{7}$ CARVALHO, Mario César. “Exposição revela um novo olhar sobre as favelas”. In: Folha de S. Paulo, 8 de abril de 2010, p. E4. Ilustrada.
} 
lajes para festas, contratam-se castings para desfiles, descobrem-se talentos exportáveis. Torna-se missão delicada o diálogo sobre sustentabilidade, transculturação e cultura cidadã. A favela Dona Marta é a grande vedete, a favela show e, de alguma forma, está exigindo maior reflexão sobre a euforia narrada pela mídia onde matéria de página inteira praticamente não comenta o teor cultural das parcerias e negociações, sublinhando o humor e deslumbramento dos atores sociais da comunidade que, segundo a matéria, nem se interessam por vezes pelas celebridades que freqüentam o morro. Se os movimentos comunitários buscam aumentar a auto-estima das comunidades, a do Dona Marta já está bem lá no alto, dispensando os encontros e ações propostas por pesquisadores como tive oportunidade de observar. Dizia a coordenadora do grupo de moda “Costurando Ideais” que não estava interessada em projetos com a UFRJ, pois, não se interessava em criar cooperativa para efeitos de poder dar recibos contra os benefícios recebidos. Segundo ela, a Prefeitura estava bem ali sem exigir nada em troca do incentivo turístico à região. A situação geral da narrativa midiática é confusa entre bondes, elevadores (no Cantagalo), muros e ações de pacificação ora retratadas como plenamente vitoriosas, ora ameaçadas pela venda de drogas a céu aberto em espaços já ocupados pelas UPPs (Unidades de Polícia Pacificadora).

A superficialidade dos relatos da mídia parecem sugerir o sucesso definitivo das periferias assediadas por diretores de filmes, artistas e turistas. O êxito está presente na manchete "Favelas viram as grandes estrelas" indústria cultural made in Rio. Por ocasião do carnaval na Marquês de Sapucaí as Escolas de Samba Portela, Unidos de Vila Isabel e Estação Primeira de Mangueira trouxeram carros alegóricos com representações bem particulares dos morros cariocas. Na Azul e Branco de Madureira, a favela simboliza com o carro “Conquistando a liberdade”, a inclusão digital como forma de contribuir para a paz no Rio. Também as UPPs são apontadas no enredo como solução para a cidade. As diversas ligações entre comunidades e a cultura da moda, da música, sem dúvida mereceriam análises mais apuradas por parte das matérias jornalísticas que preferem ressaltar as cores vivas projetadas pelas novas obras sem detalhes para o modus

\footnotetext{
${ }^{8}$ GALDO, Rafael. “Favelas viram as grandes estrelas”. In: O Globo, 14 de fevereiro de 2010, p. 18. Rio.
} 
operandi das parcerias que geram sustentabilidade. A opinião da comunidade vem narrada num registro que oscila entre passividade e deslumbramento. A desinformação sobre o assunto periferia inclui a pintura da fachada das favelas entre as quais está incluída a do Morro do Alemão que atualmente é sede da maioria dos traficantes provenientes das zonas ocupadas pelas UPPs. ${ }^{9}$

\section{Imagens periféricas}

O cinema hoje abdica em parte do fardo sociológico que carregava no cinema novo, preocupando-se mais em captar o estilo pessoal dos atores sociais. Um bom exemplo é o filme "Sonhos roubados", de Sandra Werneck, em que três amigas vivem o dia-a-dia da favela construindo seus destinos no cruzamento das relações familiares, amorosas e de trabalho. Tudo fazem pelo consumo e pelo "estilo" numa série de escolhas que nos faz pensar em Gilles Lipovetsky e seu $O$ império do efêmero ${ }^{10}$ quando fala dos processos de personificação construídos incessantemente. As meninas e seus corpos oscilam numa constelação de valores e escolhas que parecem se equilibrar e equivaler num clima de deriva que ao final do filme parece resultar em liberdade prazerosa. Transar ou não transar, pintar o cabelo ou não, escolher este ou aquele objeto, procurar o pai, fazer festa de quinze anos, ajudar o avô, namorar presidiário etc, etc. Um exemplo perfeito da deriva a que se refere Sennett $^{11}$ ao descrever o capitalismo flexível.

Nossa hipótese é que a mídia, no afã de criar novos olhares sobre a periferia, continua alternando a demonização deste mundo com a crescente implementação de ficções românticas que se inclinam em variadas direções. No cinema, valores como liberdade de opções,

\footnotetext{
${ }^{9}$ BASTOS, Isabela; MAGALHÃES, Luiz Ernesto. “Cores vivas nas favelas”. In: O Globo, 24 de fevereiro de 2010, p. 16. Rio.

${ }^{10}$ LIPOVETSKY, Gilles. O império do efêmero: a moda e seu destino nas sociedades modernas; tradução Maria Lúcia Machado. São Paulo: Companhia das Letras, 1989.

${ }^{11}$ SENNETT, Richard. A corrosão do caráter: as consequências pessoais do trabalho no novo capitalismo; tradução Marcos Santarrita, 13 ed. Rio de Janeiro: Record, 2008.
} 
estratégias de resistência e comportamentos estilosos na modelagem sex and the city são exemplos. Discutimos a real possibilidade de intervenção e recriação dos sentidos pelos atores sociais da periferia as possíveis manipulações da indústria cultural. Grande parte dos relatos da mídia contemporânea não apresenta um grau de processualidade que permita refletir sobre as interações entre a comunidade e as instituições estatais e/ou privadas que se dedicam a criação da sustentabilidade destas áreas que na cidade começam a serem ocupadas/pacificadas pelas UPPs cercadas por muros a espera da Copa do Mundo ou das Olimpíadas. Quando chegamos à Cidade do Rio de Janeiro passando pela Linha Vermelha, podemos apreciar os simulacros da favela que estes painéis substituem: casario pobre, grafites e outras representações criadas frequentemente no computador.

Nosso propósito é tentar refletir como a periferia afirma, negocia ou recusa a imagem disseminada pela mídia, o que está sendo realizado em contatos não sistemáticos com algumas comunidades. O depoimento de Ferréz é significante:

"E a mudança? Orientar sobre gravidez precoce, sobre o uso de drogas, montar uma campanha real para nosso meninos e meninas desvalorizados, estigmatizados, pelos olhos da elite, do próprio povo e por todos os meios de comunicação. Não podemos só mostrar a consequência, temos que mostrar a causa” (FERRÉZ, 2006, A3).

\section{Bibliografia:}

BASTOS, Isabela; MAGALHÃES, Luiz Ernesto. “Cores vivas nas favelas”. In: O Globo, 24 de fevereiro de 2010. Rio.

CALVINO, Ítalo. Cidades invisíveis. São Paulo: Companhia das Letras, 1990.

CARVALHO, Mario César. “Exposição revela um novo olhar sobre as favelas”. In: Folha de S. Paulo, 8 de abril de 2010. Ilustrada.

FERRÉZ. “Antropo(hip-hop) logia”. In: Folha de S. Paulo, 5 de abril de 2006. Opinião. 
FONSECA, Rodrigo. “O morro vai a Cannes”. O Globo, 16 de abril de 2010. Segundo Caderno.

GALDO, Rafael. "Favelas viram as grandes estrelas”. In: O Globo, 14 de fevereiro de 2010. Rio.

IANNI, Octavio. A era do globalismo, 2 ed. Rio de Janeiro: Civilização Brasileira, 1996.

LIPOVETSKY, Gilles. O império do efêmero: a moda e seu destino nas sociedades modernas; tradução Maria Lúcia Machado. São Paulo: Companhia das Letras, 1989.

SANSOT, Pierre. Les gens du peu. Paris: PUF, 1991.

SENNETT, Richard. A corrosão do caráter: as consequências pessoais do trabalho no novo capitalismo; tradução Marcos Santarrita, 13 ed. Rio de Janeiro: Record, 2008. 